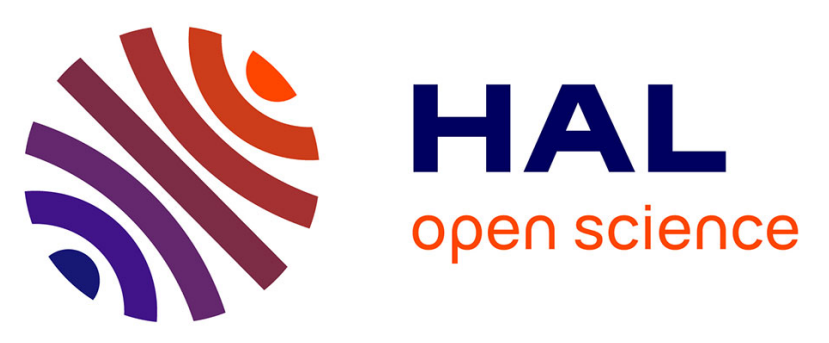

\title{
Ru-Sn-B/TiO 2 catalysts for methyl oleate selective hydrogenation. Influence of the preparation method and the chlorine content
}

María Sánchez, Vanina Mazzieri, Stéphane Pronier, María Vicerich, Catherine Especel, Florence Epron, Carlos Pieck

\section{To cite this version:}

María Sánchez, Vanina Mazzieri, Stéphane Pronier, María Vicerich, Catherine Especel, et al.. Ru-Sn$\mathrm{B} / \mathrm{TiO} 2$ catalysts for methyl oleate selective hydrogenation. Influence of the preparation method and the chlorine content. Journal of Chemical Technology and Biotechnology, 2019, 94 (3), pp.982-991. 10.1002/jctb.5849 . hal-02109660

\section{HAL Id: hal-02109660 https://hal.science/hal-02109660}

Submitted on 21 Jul 2020

HAL is a multi-disciplinary open access archive for the deposit and dissemination of scientific research documents, whether they are published or not. The documents may come from teaching and research institutions in France or abroad, or from public or private research centers.
L'archive ouverte pluridisciplinaire HAL, est destinée au dépôt et à la diffusion de documents scientifiques de niveau recherche, publiés ou non, émanant des établissements d'enseignement et de recherche français ou étrangers, des laboratoires publics ou privés. 


\section{$\mathrm{Ru}-\mathrm{Sn}-\mathrm{B} / \mathrm{TiO}_{2}$ catalysts for methyl oleate selective}

\section{hydrogenation. Influence of the preparation method and}

\section{the chlorine content}

María A. Sánchez ${ }^{1}$, Vanina A. Mazzieri ${ }^{1}$, Stéphane Pronier $^{2}$, María A. Vicerich ${ }^{1}$, Catherine Especel ${ }^{2}$, Florence Epron ${ }^{2}$, Carlos L. Pieck ${ }^{1}$

${ }^{1}$ Instituto de Investigaciones en Catálisis y Petroquímica (INCAPE) (FIQ-UNL, CONICET), Colectora Ruta Nac. № 168 Km. 0 - Paraje El Pozo - CP 3000, Santa Fe, Argentina

${ }^{2}$ Institut de Chimie des Milieux et des Matériaux de Poitiers (IC2MP), Université de Poitiers, UMR 7285 CNRS, 4 rue Michel Brunet, 86073 Poitiers cedex 9, France

Corresponding author: Carlos L. Pieck

INCAPE

Colectora Ruta Nac. Nº 168 Km. 0 - Paraje El Pozo

3000 Santa Fe, Argentina

Tel. +54-342-4511370

E-mail: pieck@fiq.unl.edu.ar

Orcid ID: orcid.org/0000-0002-5104-3364

Keywords: Methyl oleate, Selective hydrogenation, $\mathrm{Ru}-\mathrm{Sn}-\mathrm{B} / \mathrm{TiO}_{2}$ catalysts 


\section{Abstract:}

Background: Fatty alcohols are produced commercially by selective hydrogenation of fatty acid esters using copper and chromium catalysts. To reduce drastic reaction conditions, $\mathrm{Ru}-\mathrm{Sn}$ catalysts reduced with $\mathrm{NaBH}_{4}$ have been proposed. Chlorine negatively affects the selectivity and activity of this catalytic system. To get further information on why $\mathrm{Cl}$ influences the selectivity negatively, we studied the influence of the preparation method on titania-supported catalysts, which leads to catalysts with different chlorine contents.

Results: The activity and selectivity were greatly affected by the chlorine content which depends on the metal impregnation method (coimpregnation in excess of solution or coimpregnation by incipient wetness) and the support precalcination. Chlorine affects the $\mathrm{Ru}$ $\mathrm{Sn}$ metal interaction modifying the activity and selectivity. Catalysts with high $\mathrm{Ru}-\mathrm{Sn}$ interaction are more selective to oleyl alcohol. Catalyst prepared by coimpregnation method exhibits bigger particles than by incipient wetness method, with agglomerated $\mathrm{Ru}_{3} \mathrm{Sn}_{7}$ cubic phase of $50 \mathrm{~nm}$ surrounded by amorphous Ru-Sn.

Conclusion: High interaction between $\mathrm{Ru}$ and $\mathrm{Sn}$ is preferred because segregated $\mathrm{Ru}$ species are not selective for the formation of oleyl alcohol. The electronic state of $\mathrm{Ru}^{\circ}$ is very important because small variations in the electron density leads to a decrease in the adsorption of the hydrogen, or because $\mathrm{Ru}^{\circ}-\mathrm{H}$ species do not have the adequate binding energy to produce the necessary "hydride form". Ru electronic state is modified by the chlorine that surrounds it, decreasing its ability to adsorb hydrogen. 


\section{Introduction}

Fatty alcohols are important intermediates to produce surfactants, cosmetics and plasticizers. ${ }^{1}$ In general, unsaturated fatty alcohols are more expensive than saturated alcohols because of the additional cost that the process requires to protect the unsaturated $\mathrm{C}=\mathrm{C}$ double bond. In 1931, Adkins discovered copper and chromium $(\mathrm{Cu} / \mathrm{Cr})$ catalytic systems for the hydrogenation of esters. ${ }^{2}$ Similar catalysts are still used for the hydrogenation of fatty acid esters but require high pressure of reaction (25-30 MPa). To reduce drastic reaction conditions, $\mathrm{Ru}-\mathrm{Sn}$ catalysts reduced with sodium borohydride $\left(\mathrm{NaBH}_{4}\right)$ have been proposed..$^{3-7}$ In a previous work, we found that $\mathrm{Ru}-\mathrm{Sn}-\mathrm{B} / \mathrm{Al}_{2} \mathrm{O}_{3}$ catalysts prepared by coimpregnation using incipient wetness method had higher activity and selectivity than catalysts prepared by coimpregnation with excess solution. ${ }^{8}$ Besides, catalysts prepared using sodium borohydride had a high selectivity to oleyl alcohol, whereas Ru-Sn catalysts prepared without B were not selective for the formation of oleyl alcohol. ${ }^{4}$ This behavior was attributed to different degrees of interaction between $\mathrm{Ru}$ and $\mathrm{Sn} .{ }^{4,9}$

The support has a strong influence on the performances of the Ru-Sn catalysts used for the selective hydrogenation of fatty acid or fatty esters to produce oleyl alcohol. ${ }^{7,10,11}$ The support can strongly interact with the supported ruthenium oxide, affecting its reducibility, the size of the particles of $\mathrm{Ru}$ and the interaction between $\mathrm{Ru}$ and $\mathrm{Sn} .{ }^{11-13} \mathrm{In}$ the case of $\mathrm{TiO}_{2}$ support, it was reported the formation of a mixed oxide between tin and titania. ${ }^{14,15}$ The catalytic properties of the support are also modified by chlorine introduced by the metal precursors. In the case of the $\mathrm{Ru}-\mathrm{Sn} / \mathrm{Al}_{2} \mathrm{O}_{3}$ catalysts used for selective hydrogenation of fatty esters and fatty acids, it has been reported that the presence of $\mathrm{Cl}$ negatively affects the selectivity. ${ }^{7,9,16}$ For other catalytic systems, the negative influence of chlorine on the activity of $\mathrm{Ru}$ catalysts for $\mathrm{CO}$ hydrogenation and on $\mathrm{CO}$ and hydrogen chemisorptions was 
reported. ${ }^{17,18}$ Also, the activity of $\mathrm{Ru}$ catalyst is significantly degraded by chlorine in ammonia synthesis due to its electron-withdrawing property. ${ }^{19}$

In order to get further information on why $\mathrm{Cl}$ influences the selectivity negatively, we studied the effect of the preparation method on titania-supported catalysts, which leads to catalysts with different chlorine contents. Two preparation methods (coimpregnation with excess of impregnation solution and coimpregnation with the exact amount of impregnation solution, i.e. by incipient wetness) and two support precalcination temperatures (300 and 500 $\left.{ }^{\circ} \mathrm{C}\right)$ were used.

\section{Experimental}

\section{Catalysts preparation.}

Support preparation: $\mathrm{TiO}_{2}$ was synthesized from $\mathrm{TiCl}_{4}$ by the technique previously described ${ }^{20}$ One part was calcined at $300{ }^{\circ} \mathrm{C}$ and another part at $500{ }^{\circ} \mathrm{C}$ in a stream of dry air during $4 \mathrm{~h}$ to eliminate any contamination of organic compounds. The heating rate was $2{ }^{\circ} \mathrm{C} \min ^{-1}$.

Preparation by coimpregnation method $(C I)$ with excess solution: the catalyst was prepared according to the method described previously. ${ }^{8}$ Metal precursors $\left(\mathrm{RuCl}_{3} . \mathrm{xH}_{2} \mathrm{O}\right.$ and $\mathrm{SnCl}_{2} .2 \mathrm{H}_{2} \mathrm{O}$ ) as well as sodium borohydride were from Sigma Aldrich (> 99\% pure). Briefly, the support was impregnated with an aqueous solution containing the precursor salts of both metals (coimpregnation), adding an excess of solution. The solution was allowed to stand for $12 \mathrm{~h}$. Then, the samples were filtered and dried at $120^{\circ} \mathrm{C}$ for $24 \mathrm{~h}$ in stove. After that the metals were reduced with an aqueous solution of sodium borohydride, filtered again, washed and dried at $120{ }^{\circ} \mathrm{C}$ for $4 \mathrm{~h}$ under nitrogen blanketing. They were then reduced with hydrogen at $300{ }^{\circ} \mathrm{C}$ for $2 \mathrm{~h}$ and cooled down in hydrogen to room temperature. Finally, the system was flushed with nitrogen and the catalyst was put in contact with air at room temperature. 
Preparation by coimpregnation by incipient wetness method (IW): the catalyst was prepared according to the same method previously described. ${ }^{11}$ Briefly, the support was wetted with exactly the pore volume of an aqueous solution of both metal precursor salts $\left(\mathrm{RuCl}_{3} \cdot 2 \mathrm{H}_{2} \mathrm{O}\right.$, and $\mathrm{SnCl}_{2} \cdot 2 \mathrm{H}_{2} \mathrm{O}$ ) in the required amounts to achieve the desired metal content. Wetted samples were left to stand for $12 \mathrm{~h}$, then reduced by the addition of aqueous sodium borohydride, filtered, washed with water until neutrality, and dried during $4 \mathrm{~h}$ at $120{ }^{\circ} \mathrm{C}$ under $\mathrm{N}_{2}$ flowing. Finally, the samples were reduced according to the same protocol as for CI catalyst.

The catalysts were called $\mathrm{T}^{\circ} \mathrm{C}$-IW or $\mathrm{T}^{\circ} \mathrm{C}-\mathrm{CI}$, where $\mathrm{T}$ is the calcination temperature of the support $\left(300\right.$ or $\left.500{ }^{\circ} \mathrm{C}\right)$, IW and CI are the methods of incorporation of metals (coimpregnation by incipient wetness or coimpregnation in excess solution, respectively). The theoretical loadings of Ru and $\mathrm{Sn}$ were 1.5 and $3.0 \mathrm{wt} \%$, respectively, using both preparation methods.

\section{Characterization methods.}

Elemental analysis: the composition of the metal phase was determined by inductively coupled plasma optical emission spectroscopy (ICP-OES, Perkin Elmer, Optima 2100 DV) after digestion in an acid solution. The chlorine content was determined spectrophotometrically by the mercury thiocyanate method using a Metrolab 1700 Spectrophotometer.

Textural properties: the specific surface area (BET method), total pore volume, and pore size distribution (BJH method) were determined by nitrogen adsorption. The catalyst samples were degassed at $200{ }^{\circ} \mathrm{C}$ for $2 \mathrm{~h}$, and then the nitrogen adsorption isotherm was determined at -196 ${ }^{\circ} \mathrm{C}$ with a Micromeritics ASAP 2020.

X-Ray Diffraction (XRD): X-ray diffractograms were performed with a Shimadzu XD-1 diffractometer $(\mathrm{CuK} \alpha$ radiation filtered with $\mathrm{Ni})$. The spectra were taken in the range of $2 \theta$ between $20^{\circ}$ and $70^{\circ}$ with a sampling rate of $1.2^{\circ} \mathrm{min}^{-1}$. 
Temperature-Programmed Reduction (TPR): the equipment (Ohkura TP 2002S) and conditions have been described elsewhere. ${ }^{4}$ A known mass of catalyst was treated in air at $450{ }^{\circ} \mathrm{C}$ for $1 \mathrm{~h}$, then cooled down to room temperature under air flow. Then, Ar was used for 15 minutes. Finally, a reducing mixture $\left(5 \% \mathrm{H}_{2} / \mathrm{Ar}\right)$ was fed and the temperature was increased linearly from $25{ }^{\circ} \mathrm{C}$ to $700{ }^{\circ} \mathrm{C}$ at a rate of $10{ }^{\circ} \mathrm{C} \mathrm{min}^{-1}$.

Cyclohexane $(\mathrm{CH})$ dehydrogenation: the reaction conditions and the method of analysis of the reaction products have been reported elsewhere. ${ }^{4}$ In brief, the catalyst $(50 \mathrm{mg}$ ) was charged and activated with $\mathrm{H}_{2}$ (flow rate $36 \mathrm{~mL} \mathrm{~min}^{-1}$ ) at $300{ }^{\circ} \mathrm{C}$ during $1 \mathrm{~h}$ before reaction. The reaction was carried out at $300{ }^{\circ} \mathrm{C}$, under atmospheric pressure and with a molar ratio $\mathrm{H}_{2} / \mathrm{CH}=30$. Cyclohexane was provided by Sigma Aldrich (> 99.9\% pure).

X-Ray Photoelectron Spectroscopy (XPS): XPS measurements were carried out using a multitechnique system (SPECS) equipped with a dual Mg/Al X-ray source and a hemispherical PHOIBOS 150 analyzer (Germany) operating in the fixed analyzer transmission (FAT) mode following the technique described earlier. ${ }^{4}$ The XPS analyses were performed on the solids after treatment with hydrogen/argon at $300{ }^{\circ} \mathrm{C}$. Calibration of the spectra was performed with the $\mathrm{Ti}$ $2 \mathrm{p}_{3 / 2}$ line $(455 \mathrm{eV})$ from a $\mathrm{TiO}_{2}$ support. The data treatment was performed with the Casa XPS program (Casa Software Ltd., UK). ${ }^{4}$

Transmission Electron Microscopy (TEM): The analyses were carried out with a Jeol Jem 2100 UHR microscope equipped with a Si (Li) detector for the EDS and a Gatan ultrascan $2 \mathrm{kx} 2 \mathrm{k}$ camera. The samples were prepared in ethanol and placed in an ultrasonic bath without prior grinding. FFT and electronic diffraction interpretations were performed using the HIGHSCORE (XRD) software, the ICDD-PDF2 file for searching the sample phases, the CARINE CRISTALLOGRAPHY software to simulate the projection of diffraction patterns, or FFTs and IMAGE.J software to measure particles size for histograms. For each catalyst, 
approximately 500 metal particles were observed, and the distribution of particle sizes was measured. The mean particle diameter $(\mathrm{d} P)$ was calculated as the following:

$$
d_{p}=\frac{\sum n_{i} d_{i}^{3}}{\sum n_{i} d_{i}^{2}}
$$

where $n_{i}$ is the number of particles of diameter $d_{i}$.

Methyl oleate (9-octadecen-1-ol) hydrogenation: The experiments were carried out in a stainless-steel autoclave reactor $\left(280 \mathrm{~cm}^{3}\right.$ capacity). The reaction conditions ( $1 \mathrm{~g}$ of catalyst, $290{ }^{\circ} \mathrm{C}$ and $5 \mathrm{MPa}$ ) and the method for the analysis of the reaction products were previously reported. ${ }^{21}$ In summary, reaction products were analyzed by GC (Shimadzu GC-200) using a Chevron ZB-FFAP capillary column (length: $30 \mathrm{~m}$, inner diameter: $0.25 \mathrm{~mm}$ ), with the following conditions: injector temperature of $220^{\circ} \mathrm{C}$, column temperature of $200{ }^{\circ} \mathrm{C}$ for $1 \mathrm{~min}$, $2{ }^{\circ} \mathrm{C} \mathrm{min}-1$ ramp up to $260{ }^{\circ} \mathrm{C}$ and then isothermal; detector (FID) temperature of $265{ }^{\circ} \mathrm{C}$; $\mathrm{N}_{2}$ carrier gas. Identification of reaction products was previously done by GC-MS (Shimadzu QP5000), using the same capillary column. Only oleyl alcohol, methyl stearate, stearyl alcohol and methyl oleate were detected as significant compounds in the reactor. The reagents (methyl oleate and n-dodecane) were provided by Sigma Aldrich (99\% purity).

\section{Results and discussion}

Table 1 shows the specific surface area, pore volume and pore size values of the studied catalysts. It is seen that the IW and CI catalysts for the supports calcined at $500{ }^{\circ} \mathrm{C}$ have pores almost twice the size of those calcined at $300{ }^{\circ} \mathrm{C}$, while the surface area is strongly decreased (from 93 to 38 and 103 to $48 \mathrm{~m}^{2} \mathrm{~g}^{-1}$ for the CI and IW samples respectively). In order to determine whether the specific surface area modification is due to a change in the structure of the titania support, XRD analyses were performed on the catalysts. Rutile, anatase and brookite are the most common $\mathrm{TiO}_{2}$ phases. Pure bulk anatase begins to transform irreversibly to rutile 
in air at about $600{ }^{\circ} \mathrm{C}$; nevertheless, the transition temperatures vary between $400-1200{ }^{\circ} \mathrm{C} .{ }^{22}$ The wide XRD patterns (Fig. 1) of the samples display five $\mathrm{TiO}_{2}$ diffraction lines centered at $25.3^{\circ}, 37.8^{\circ}, 48.0^{\circ}, 54.9^{\circ}$ and $62.8^{\circ}$ corresponding to anatase crystal planes. ${ }^{23}$ It means that the pre-calcination temperature or preparation method does not modify the support phase structure. However, the pre-calcination temperature of the support has an influence on the average particle size of $\mathrm{TiO}_{2}$ anatase. As expected, the estimated average particle size of anatase determined by the Scherrer formula based on the diffraction peak at $25.3^{\circ}$ is high on the support calcined at higher temperature, as it can be seen in Table 1.

Table 2 displays the metal content values, chlorine percentage and cyclohexane conversion values obtained for the four catalysts. For all catalysts, the Ru and Sn contents were slightly lower than the expected theoretical values of 1.5 and $3.0 \mathrm{wt} \%$, respectively. In addition, Table 2 shows that the catalyst prepared by a given method with the support calcined at $500{ }^{\circ} \mathrm{C}$ has a lower chlorine content than the one prepared on the support calcined at $300{ }^{\circ} \mathrm{C}$. This is because during the calcination step, the support $\left(\mathrm{TiO}_{2}\right)$ gives off water, which entrains the residual chlorine coming from the $\mathrm{TiCl}_{4}$ precursor used for the preparation of the support. The higher the calcination temperature, the greater the water elimination and consequently, the lower amount of retained chlorine. The IW method also produces catalysts with lower chlorine contents, probably due to the more efficient washing performed after the impregnation step of the metal precursors.

The temperature programmed reduction profiles of $\mathrm{Ru}$ and $\mathrm{Sn}$ monometallic catalysts supported on $\mathrm{TiO}_{2}$ calcined at $500{ }^{\circ} \mathrm{C}$ were previously reported. ${ }^{11}$ Boron was found to decrease the reduction temperature of Ru oxides from 128 to $110^{\circ} \mathrm{C}$, whereas the Sn oxides were reduced at a higher temperature starting their reduction at $450{ }^{\circ} \mathrm{C}$ with a maximum around $600{ }^{\circ} \mathrm{C}$. The shift in the Ru and Sn reduction temperature peaks shows that both metals were interacting with B. The electronegativity of the $\mathrm{Ru}, \mathrm{Sn}$ and B are 2.20; 1.96 and 2.02 (Pauling). Therefore, B is 
prone to give electrons to $\mathrm{Ru}$ and remove electrons from $\mathrm{Sn}$. This could explain the different influence of B on the metal oxides reduction.

Fig. 2 shows that for all bimetallic catalysts the maximum of the reduction peak of $\mathrm{Ru}$ oxides occurs at a higher temperature than for the $\mathrm{Ru}$ monometallic catalyst. This could be because the $\mathrm{Sn}$ is in strong interaction with the Ru retarding the reduction. The tin surface species would inhibit the contact of hydrogen with ruthenium atoms. In addition, when the support was calcined at $300{ }^{\circ} \mathrm{C}$, a peak attributed to the reduction of segregated Sn species could be observed at a high temperature $\left(>600{ }^{\circ} \mathrm{C}\right)$. When the support was calcined at $500{ }^{\circ} \mathrm{C}, \mathrm{Sn}$ was reduced at a lower temperature $\left(400{ }^{\circ} \mathrm{C}\right.$ and $250{ }^{\circ} \mathrm{C}$ for $\mathrm{CI}$ and IW catalysts, respectively). This indicates that there are $\mathrm{Sn}$ oxide particles close to $\mathrm{Ru}$ of which reduction is catalyzed by $\mathrm{Ru}$, especially for the IW sample. In conclusion, the TPR results show that for the support precalcined at $500^{\circ} \mathrm{C}$ there are $\mathrm{Ru}, \mathrm{Sn}$ and $\mathrm{B}$ species in strong interaction, the strongest $\mathrm{Ru}-\mathrm{Sn}$ interaction being obtained in the IW catalyst. There are also more segregated Sn particles on the catalysts prepared with the support pre-calcined at $300{ }^{\circ} \mathrm{C}$ than on those prepared on the support pre-calcined at $500{ }^{\circ} \mathrm{C}$.

Cyclohexane dehydrogenation is a useful reaction to measure the activity of the metallic function. Additional experiments with the monometallic Sn and Ru catalysts showed that only the monometallic Ru catalyst was active for cyclohexane dehydrogenation. On the one hand, it is widely known that the reaction is "facile" (structure-insensitive) because it does not require a particular ensemble of neighboring metal atoms to form adsorbate bonds with the proper strength $^{24,25}$. On the other hand, benzene is the only reaction product obtained in the reaction conditions used. Table 2 shows that the lower support pre-calcination temperature leads to catalysts with the highest values of cyclohexane conversion. In addition, by comparing catalysts with the same pre-calcination temperature, the IW ones lead to lower conversion values than the CI ones. Since Ru is active-for the dehydrogenation of cyclohexane, while $\mathrm{Sn}$ is inactive, 
the lower activity of the IW catalysts could be due to a higher Ru-Sn interaction or simply because $\mathrm{Ru}$ accessibility is lower on the IW catalysts. Sn would decrease Ru activity because $\mathrm{Sn}$ deposited onto the $\mathrm{Ru}$ blocks the active sites (geometrical effect) or there are $\mathrm{Sn}$ atoms deposited near to $\mathrm{Ru}$ atoms which modify the electronic state of $\mathrm{Ru}$ turning less active (electronic effect). These results agree with the TPR profiles, since the support calcined at the lowest temperature showed a higher amount of segregated $\mathrm{Sn}$; consequently, the dehydrogenating activity of Ru was less affected by Sn. It is important to point out that there is no correlation between the chlorine content of the catalysts and cyclohexane conversion, since the reaction is catalyzed by the metal function.

XPS analyses were performed to gain information about the electronic states of the surface Ru and Sn species. For a sake of simplicity, Fig. 3 only shows the XPS spectra of the bimetallic $500{ }^{\circ} \mathrm{C}$-IW and $300{ }^{\circ} \mathrm{C}-\mathrm{CI}$ catalysts, i.e. the best and worst catalysts in relation to the selectivity to oleyl alcohol. Fig. 3 shows the 276-292 binding energy (BE) range where the peaks attributed to $\mathrm{Ru}$ are located. Since the $\mathrm{C} 1 \mathrm{~s}$ peak at $284.6 \mathrm{eV}$ of surface adventitious carbon overlaps with $\mathrm{Ru} 3 \mathrm{~d}_{3 / 2}$, the peak of $\mathrm{Ru} 3 \mathrm{~d}_{5 / 2}$ was employed to determine the chemical state of $\mathrm{Ru}$ in all cases. To make the figure easier to analyze, only the $\mathrm{Ru} 3 \mathrm{~d}$ 5/2 peaks are shown. The XPS results show that $\mathrm{Ru}^{\circ}$ metallic species are present in all catalysts, with $\mathrm{BE}$ values in the range between 279.2 and $280.1 \mathrm{eV}$, in accordance with the values for metallic $\mathrm{Ru}$ reported in the literature, ${ }^{26-28}$ while the peak at $284.3-284.8 \mathrm{eV}$ is attributed to $\mathrm{Ru} 3 \mathrm{~d} 5 / 2$ oxidized species. The preparation method has influence on the reduction of $\mathrm{Ru}$ because the $\mathrm{Ru}^{\delta+}$ species of the catalysts prepared by CI method displayed BE values around $0.5 \mathrm{eV}$ higher than that of the IW catalyst (Figs 3 and 4). These results are confirmed by a higher fraction of $\mathrm{Ru}^{\circ} /\left(\mathrm{Ru}^{\circ}+\mathrm{Ru}^{\delta+}\right)$ for the IW catalysts reported in Table 3. This phenomenon could be due to chlorine deposited on the support because the increase in the binding energy of the $\mathrm{Ru}^{\delta+}$ species correlates with the chlorine content. Chlorine (electrophilic compound) would produce an increase of the BE of 
the $\mathrm{Ru}^{\delta+}$ by inductive effect as seen in Fig. 4. The harmful effect of chlorine on the reduction of $\mathrm{Ru}$ was also reported in the literature. ${ }^{29-31}$ Mazzieri et al. speculated that $\mathrm{Ru}^{\mathrm{n}+}$ species on these catalysts are associated with chlorine species. ${ }^{31}$

The low BE difference $(<0.5 \mathrm{eV})$ between $\mathrm{Sn}^{2+}$ and $\mathrm{Sn}^{4+}$ species makes it almost impossible to distinguish them by XPS. A small peak in the range 484-485 eV and a greater peak at $486.1 \mathrm{eV}$ were found for the $\mathrm{Sn} 3 \mathrm{~d}_{5 / 2}$ band (results not shown). According to Rodina et al., the first peak can be attributed to $\mathrm{Sn}^{\circ}$ and the second one to $\mathrm{Sn}^{\mathrm{n}+}$ species. ${ }^{32}$ The $\mathrm{Sn}^{\circ} /\left(\mathrm{Sn}^{\circ}+\mathrm{Sn}^{\mathrm{n}}\right)$ fraction is lower than 0.2 for all the catalysts. These results agree with those reported by other authors, since the complete reduction of tin to the zero valent state is very difficult to achieve. ${ }^{33,34}$

The $\mathrm{Sn} / \mathrm{Ti}, \mathrm{Ru} / \mathrm{Ti}$ and $\mathrm{Sn} / \mathrm{Ru}$ atomic ratios calculated from the elemental analysis are about $0.02,0.01$ and 1.92 , respectively. The $\mathrm{Sn} / \mathrm{Ti}$ and $\mathrm{Ru} / \mathrm{Ti}$ surface atomic ratios obtained by XPS are displayed in Table 3. The catalysts prepared on the support calcined at $500{ }^{\circ} \mathrm{C}$ had lower $\mathrm{Ru} / \mathrm{Ti}$ and $\mathrm{Sn} / \mathrm{Ti}$ surface ratios than those prepared with the support calcined at $300{ }^{\circ} \mathrm{C}$ regardless of the preparation method used. Moreover, by comparing the catalysts prepared on the support calcined at the same temperature, the CI catalysts had lower $\mathrm{Ru} / \mathrm{Ti}$ and $\mathrm{Sn} / \mathrm{Ti}$ surface atomic ratios than the IW ones. It is important to note that the $\mathrm{Ru} / \mathrm{Ti}$ and $\mathrm{Sn} / \mathrm{Ti}$ surface ratios are much higher than those expected from the bulk analysis, in agreement with the results reported by Gu et al. ${ }^{35}$ and Elmasides et al. ${ }^{36}$ For a $2 \% \mathrm{Ru} / \mathrm{TiO}_{2}$ catalyst after reduction at 550 ${ }^{\circ} \mathrm{C}$, Elmasides et al. reported that the surface was dramatically enriched in $\mathrm{Ru}$ with a $\mathrm{Ru} / \mathrm{Ti}$ surface ratio $>1 .{ }^{36}$ Similar results were found for $\mathrm{Ru}-\mathrm{Sn} / \mathrm{Al}_{2} \mathrm{O}_{3}$ catalysts, since Rodina et al. reported that the $\mathrm{Sn} / \mathrm{Al}$ and $\mathrm{Ru} / \mathrm{Al}$ surface ratios were ten and four times bigger than the bulk atomic ratios, respectively. ${ }^{32}$ The $\mathrm{Sn} / \mathrm{Ru}$ surface ratio was also higher than the bulk ratio.

XPS data (not shown) indicated a decrease in the amount of chlorinated species at higher calcination temperatures in accordance with the values reported in Table 1. 
An exhaustive analysis of the samples by TEM and EDX was performed. On the $500{ }^{\circ} \mathrm{C}$ CI catalyst, crystallized Ru-Sn phase agglomerates of $50 \mathrm{~nm}$ were observed. The EDX analy ses show a very homogeneous ratio of $\mathrm{Sn} / \mathrm{Ru}=7 / 3$. The images in FFT and HAADF imaging confirmed the presence of a $\mathrm{Ru}_{3} \mathrm{Sn}_{7}$ phase of cubic structure. Also, small particles ( $\mathrm{Sn}$ and $\mathrm{Ru}$ phase) and characteristic tin oxide particles with their "great distance" $\left(\mathrm{d}_{\mathrm{hk} 1}=0.3359 \mathrm{~nm}\right.$ for plane (110) of tetragonal $\mathrm{SnO}_{2}$ ) were observed. There are areas consisting essentially of $\mathrm{SnO}_{2}$.

On the $300{ }^{\circ} \mathrm{C}-\mathrm{CI}$ catalyst, $\mathrm{Ru}$-Sn phase agglomerates, corresponding to $\mathrm{Ru}_{3} \mathrm{Sn}_{7}$, of about $50 \mathrm{~nm}$ but less well crystallized and more numerous than on $500{ }^{\circ} \mathrm{C}$-CI catalyst were found. Also, EDX analyses, FFT images as well as HAADF imaging confirmed the presence of $\mathrm{Ru}_{3} \mathrm{Sn}_{7}$ phase of cubic structure. There were also very small particles dispersed on $\mathrm{TiO}_{2}$ for which the diffraction was very difficult to obtain and whose EDX detection was low with a $\mathrm{Sn} / \mathrm{Ru}$ ratio of about 4/1. Some particles of Sn oxide were also detected. Complementary large analysis on dispersed particles showed that $\mathrm{Sn} / \mathrm{Ru}$ ratio were between $90 / 10$ and $80 / 20$, therefore with higher Sn contents than on $500{ }^{\circ} \mathrm{C}$-CI catalyst.

In the case of the $500{ }^{\circ} \mathrm{C}$-IW catalyst, very small agglomerates of RuSn 2 phase with particles size of $5 \mathrm{~nm}$ were observed. This phase can only be observed in electronic diffraction, since it seems to be covered by an amorphous phase containing $\mathrm{Ru}$ and $\mathrm{Sn}$. There were also dispersed particles on the support with sizes between 4 and $5 \mathrm{~nm}$ (atomic $\mathrm{Sn} / \mathrm{Ru}$ ratio between 10/90 to 20/80) and between 2 and $3 \mathrm{~nm}$ (with metallic contents very variable, $\mathrm{Sn} / \mathrm{Ru}$ atomic ratio between $70 / 30$ and 20/80). The electron diffractions demonstrated that the observed phases are tetragonal $\mathrm{RuSn}_{2}$ and $\mathrm{Ru}_{3} \mathrm{Sn}_{7}$.

TEM and EDX analysis of the $300{ }^{\circ} \mathrm{C}$-IW catalyst showed agglomerated particles of about $30 \mathrm{~nm}$ of $\mathrm{Ru}-\mathrm{Sn}$ phase less crystallized than on $300{ }^{\circ} \mathrm{C}$-CI catalyst. These particles have a $\mathrm{Sn} / \mathrm{Ru}$ atomic ratio between $3 / 7$ to $1 / 1$. It is also possible to observe small particles of about 1-4 $\mathrm{nm}$ gathering hexagonal or cubic $\mathrm{Ru}$, tetragonal $\mathrm{SnO}_{2}$, or cubic $\mathrm{Ru}_{3} \mathrm{Sn}_{7}$ phases. It is 
important to point out that the "wide analyses" showed that the $\mathrm{Sn} / \mathrm{Ru}$ ratios are 30/70 or 80/20. Therefore, the bimetallic particles are very heterogeneous. Also, particles dispersed on $\mathrm{TiO}_{2}$ with atomic $\mathrm{Sn} / \mathrm{Ru}$ ratio about 5/95 were found by EDX analyses.

It should be noted that in all the catalysts there was a difference between the $\mathrm{Sn} / \mathrm{Ru}$ ratio determined by the crystallographic structures and the EDX analyses. This could be explained by the fact that the particles are crystallized but they undoubtedly contain an amorphous surrounded Ru-Sn metal phase. The "wide analysis" by EDX of the surface shows that $\mathrm{Sn} / \mathrm{Ru}$ atomic ratio on the IW catalysts is lower than on the CI catalysts.

Figs 5 and 6 show typical TEM pictures and metal size distribution corresponding to CI and IW catalysts, respectively. It is important to point out that the big agglomerates of about 30-50 $\mathrm{nm}$ were not considered for calculating the metal size distribution, which probably leads to an underestimation of the mean metallic particle size, especially on CI catalysts.

Fig. 7 shows the methyl oleate conversion as a function of the reaction time. All the catalysts showed a similar initial activity. Differences in catalytic activity started to be marked at about $60 \mathrm{~min}$. Catalysts with high cyclohexane dehydrogenation activity also had high hydrogenation activity to convert methyl oleate (Table 2 and Fig. 7), except for the $500{ }^{\circ} \mathrm{C}$-IW catalyst, which presents the lowest cyclohexane conversion but the highest methyl oleate one at the end of the reaction. This might indicate that both reactions take place on different active sites. Cyclohexane dehydrogenation occurs on surface $\mathrm{Ru}$, while $\mathrm{Sn}$ is inactive and even negatively affects the Ru activity by an electronic or geometric effect. The geometric effect involves the blocking of active Ru ensembles by the added modifier atoms. The electronic effect corresponds to the modification of the Ru electronic density due to an interaction with $\mathrm{Sn}$ neighboring atoms. Such electronic modification would in turn change the adsorption energy of the chemical species participating in the catalytic reaction. It has been proved that both effects are important. ${ }^{37,38}$ Moreover, the hydrogenation of methyl oleate is catalyzed by Ru and 
$\mathrm{Sn}$ in strong interaction. ${ }^{4,6,28,39-41}$ More recently, Rodina et al. proposed that crystalline $\mathrm{Ru}_{\mathrm{x}} \mathrm{Sn}_{\mathrm{y}}$ structures with variable composition were the active component of the selective hydrogenation catalyst. ${ }^{32}$ The high activity was attributed to $\mathrm{Ru}^{\circ}$ sites interacting with $\mathrm{Sn}^{2+}$ or $\mathrm{Sn}^{4+}$ Lewis acid sites. ${ }^{6}$ It is also possible that the lower chlorine content of the $500{ }^{\circ} \mathrm{C}$-IW catalyst favors the conversion of methyl oleate because chlorine decreases the Ru-Sn interaction. ${ }^{7,9}$

Fig. 8 shows conversion values at the end of the reaction as a function of the $\mathrm{Sn} / \mathrm{Ru}$ atomic ratio obtained by XPS. As the $\mathrm{Sn} / \mathrm{Ru}$ ratio increases, the catalyst appears to be less active. At high $\mathrm{Sn} / \mathrm{Ru}$ ratios, Sn could encapsulate Ru and thereby block its catalytic activity. Fig. 9 shows values of selectivity to oleyl alcohol (desired product) as a function of reaction time. As expected, selectivity goes through a maximum as a function of the reaction time since oleyl alcohol is an intermediate reaction product, being transformed to stearyl alcohol at higher reaction times. $\mathrm{Sn} / \mathrm{Ru}$ atomic ratios equal to 2 or 4 have been reported as the optimal values favoring the formation of the unsaturated alcohol. ${ }^{3,7,28,41}$ The values reported in Table 3 show that the prepared catalysts have a $\mathrm{Sn} / \mathrm{Ru}$ surface ratio much higher than the optimum. By EDX analysis, it was found that only the catalyst $500{ }^{\circ} \mathrm{C}-\mathrm{IW}$, the most selective to oleyl alcohol, displays the $\mathrm{RuSn}_{2}$ tetragonal phase.

In addition, catalysts prepared with the support previously calcined at $500{ }^{\circ} \mathrm{C}$ are seen to be more selective to the desired product (oleyl alcohol) than those prepared with the support calcined at $300{ }^{\circ} \mathrm{C}$ regardless of the preparation method. As previously reported, good selectivity to oleyl alcohol is achieved when there is a strong Ru-Sn interaction. TPR and cyclohexane dehydrogenation have shown that a previous calcination of the support at $500{ }^{\circ} \mathrm{C}$ leads to a strong Ru-Sn interaction, probably due to the elimination of chlorine. Echeverri et al. have reported that chlorine prevents a strong interaction between $\mathrm{Ru}$ and $\mathrm{Sn}$ species, thus leading to catalysts with low selectivity to oleyl alcohol. ${ }^{9}$ 
Fig. 10 shows the selectivity to oleyl alcohol, the sum of the selectivities to stearyl alcohol and methyl stearate, and the sum of the selectivity to oleyl and stearyl alcohol as a function of the activity for dehydrogenation cyclohexane. With the increase in the cyclohexane dehydrogenation activity, the selectivity to oleyl alcohol decreases as well as the selectivity to oleyl alcohol + stearyl alcohol. This can be explained by considering that cyclohexane dehydrogenation is catalyzed by $\mathrm{Ru}$, while the selective hydrogenation of methyl oleate to oleyl alcohol occurs on $\mathrm{Ru}$ species in strong interaction with $\mathrm{Sn}$. Besides, the sum of the selectivities to stearyl alcohol and methyl stearate, i.e. the selectivity for hydrogenation of the $\mathrm{C}=\mathrm{C}$ double bond increases with the cyclohexane dehydrogenation activity. This indicates that isolated $\mathrm{Ru}$ preferably hydrogenates the $\mathrm{C}=\mathrm{C}$ double bond.

Fig. 11 shows the maximum selectivity to oleyl alcohol obtained in each catalyst as a function of the chlorine content. The higher selectivity to oleyl alcohol is obtained on the catalyst of lower $\mathrm{Cl}$ content. However, this correlation is not linear and after a certain threshold value, the ability to produce oleyl alcohol remains constant.

To explain the results, it is necessary to analyze the reaction mechanism and the active sites involved in the reaction. The reaction mechanism proposed for the selective hydrogenation of methyl oleate to oleyl alcohol is direct hydrogenation or stepwise hydrogenation via the formation of an aldehyde intermediate. ${ }^{6,28}$ In both mechanisms, the oxygen of the $\mathrm{C}=\mathrm{O}$ group is bonded to Sn oxides species which must be in strong interaction with $\mathrm{Ru}$.,6,7,28 A similar model was proposed for the $\mathrm{Ru}-\mathrm{Sn}-\mathrm{B} / \mathrm{TiO}_{2}$ catalyst where the $\mathrm{Sn}$ oxides species are replaced by $\mathrm{Ti}^{3+}$ species. ${ }^{12}$ Basically, the direct hydrogenation mechanism proposes that electron-rich $\mathrm{Ru}^{\circ}$ activates the $\mathrm{H}_{2}$ into a "hydride form". $\mathrm{Sn}^{2+}$ or $\mathrm{Sn}^{4+}$ Lewis acid sites, which are in interaction with $\mathrm{Ru}$, polarize the carbonyl of the ester, facilitating the hydrogen transfer from an adjacent $\mathrm{Ru}-\mathrm{H}$ site. The hydrogen activated on ruthenium attacks the carbon atom of the carbonyl groups and an acetal of tin is formed. 
The chlorine present in the support would modify the electronic state of Ru, mainly of the $\mathrm{Ru}$ oxidized species (changing the BE, see Fig. 4). By inductive effect, the electronic state of the $\mathrm{Ru}^{\circ}$ is also changed. Moreover, chlorine inhibits the reduction of $\mathrm{Ru}$ to the metallic state (Table 3). Therefore, the adsorption of hydrogen on $\mathrm{Ru}^{\circ}$ is disturbed. This alters the attack by the hydrogen of the carbon atom of carbonyl group, thus leading to a lower selectivity to alcohol. The active sites for the reaction proposed by several researchers are formed by $\mathrm{Sn}$ and $\mathrm{Ru}$ in strong interaction with $\mathrm{Sn} / \mathrm{Ru}$ atomic ratio of $2 .^{3,7,41}$ The TEM and EDX results showed that $500{ }^{\circ} \mathrm{C}$-IW catalyst, the most selective to oleyl alcohol, possesses the highest amount of $\mathrm{RuSn}_{2}$ tetragonal phase and big agglomerates of $\mathrm{Ru}_{3} \mathrm{Sn}_{7}$ phase were not observed.

The main advantage of the $\mathrm{Ru}-\mathrm{Sn}-\mathrm{B} / \mathrm{TiO}_{2}$ catalyst in comparison to the commercial copper chromite catalyst is the drastic reduction of the working pressure to 3-5 MPa, while the reaction temperature is similar. The commercial processes also have a higher yield to stearyl alcohol. ${ }^{21}$ However a higher yield to fatty alcohol could be obtained in our case by optimizing the reaction conditions, especially the residence time, because stearyl alcohol is the final reaction product. In this sense high selectivity to stearyl alcohol could be obtained at high values of residence time in a continuous reactor. Long residence times would be obtained at high values of the catalyst mass to feed flowrate ratio.

\section{Conclusions}

It was found that the activity and selectivity were greatly affected by the chlorine content which depend on, the metal impregnation method (coimpregnation by incipient wetness or in excess solvent) and the support pre-calcination treatment. It has been proved that it is better to pre-treat the support at high temperature $\left(500{ }^{\circ} \mathrm{C}\right)$ to remove more chlorine to obtain more selective catalysts. 
The electronic state of $\mathrm{Ru}^{\circ}$ is very important because small variations in the electron density lead to a decrease in the adsorption of the hydrogen. This electronic state is modified by the chlorine surrounding the $\mathrm{Ru}$ atoms.

Catalysts prepared by $\mathrm{CI}$ method exhibit bigger agglomerated $\mathrm{Ru}_{3} \mathrm{Sn}_{7}$ cubic phase of 50 nm surrounded by amorphous Ru-Sn than those prepared by the IW method. However, big agglomerates are also found on the $300{ }^{\circ} \mathrm{C}$-IW catalyst but they are smaller $(30 \mathrm{~nm})$. The 500 ${ }^{\circ} \mathrm{C}$-IW catalyst does not present big agglomerates. CI catalysts present a bimodal particles size distribution, with small particles lower than $2.5 \mathrm{~nm}$ and agglomerates of $50 \mathrm{~nm}$. The wide analysis by EDX of the surface shows that $\mathrm{Sn} / \mathrm{Ru}$ atomic ratio determined on the IW catalysts is lower than on the CI catalysts.

The experimental results clearly show that sites involved in the hydrogenation of methyl oleate and in the dehydrogenation of cyclohexane are different.

\section{Acknowledgements}

This work had the financial support of Consejo Nacional de Investigaciones Científicas y Técnicas and the Universidad Nacional del Litoral (Project CAI+D) - Argentina.

\section{References}

1 Knaut J and Richtler HJ, Trends in industrial uses of palm and lauric oils. J Am Oil Chem Soc 62:317-27 (1985).

2 Adkins $\mathrm{H}$ and Connor R, The catalytic hydrogenation of organic compound s over copper chromite. J Am Chem Soc 53:1091-5 (1931).

3 Narasimhan CS, Deshpande VM and Ramnarayan K, Selective hydrogenation of methyl oleate to oleyl alcohol on mixed ruthenium-tin boride catalysts. Appl Catal 48:L1-6 (1989). 
4 Sánchez MA, Mazzieri VA, Sad MR, Grau R and Pieck CL, Influence of preparation method and boron addition on the metal function properties of Ru-Sn catalysts for selective carbonyl hydrogenation. J Chem Technol Biotechnol 86:447-53 (2011).

5 Piccirilli A, Pouilloux Y, Pronier S and Barrault J, Selective hydrogenation of methyl oleate into oleyl alcohol in the presence of ruthenium-tin-supported catalysts. Bull Soc Chim Fr 132:1109-17 (1995).

6 Deshpande VM, Ramnarayan K and Narasimhan CS, Studies on ruthenium-tin boride catalysts II. Hydrogenation of fatty acid esters to fatty alcohols. J Catal 121:174-82 (1990).

7 Cheah KY, Tang TS, Mizukami F, Niwa S ichi, Toba M and Choo YM, Selective hydrogenation of oleic acid to 9-octadecen-1-ol: Catalyst preparation and optimum reaction conditions. J Am Oil Chem Soc 69:410-6 (1992).

8 Sánchez MA, Mazzieri VA, Sad MR and Pieck CL, Influence of the operating conditions and kinetic analysis of the selective hydrogenation of methyl oleate on $\mathrm{Ru}-\mathrm{Sn}-\mathrm{B} / \mathrm{Al}_{2} \mathrm{O}_{3}$ catalysts. React Kinet Mech Catal 107:127-39 (2012).

9 Echeverri DA, Marín JM, Restrepo GM and Rios LA, Characterization and carbonylic hydrogenation of methyl oleate over $\mathrm{Ru}-\mathrm{Sn} / \mathrm{Al}_{2} \mathrm{O}_{3}$ : Effects of metal precursor and chlorine removal. Appl Catal A Gen 366:342-7 (2009).

10 Mendes M. J, Santos OAA, Jordão E and Silva AM, Hydrogenation of oleic acid over ruthenium catalysts. Appl Catal A Gen 217:253-62 (2001).

11 Sánchez MA, Mazzieri VA, Vicerich MA, Vera CR and Pieck CL, Influence of the Support Material on the Activity and Selectivity of Ru-Sn-B Catalysts for the Selective Hydrogenation of Methyl Oleate. Ind Eng Chem Res 54:6845-54 (2015).

12 Corradini SA d.S, Lenzi GG, Lenzi MK, Soares CMF and Santos OAA, Characterization and hydrogenation of methyl oleate over $\mathrm{Ru} / \mathrm{TiO}_{2}, \mathrm{Ru}-\mathrm{Sn} / \mathrm{TiO}_{2}$ catalysts. J Non Cryst Solids 354:4865-70 (2008). 
13 Bond GC, Preparation and properties of vanadia/titania monolayer catalysts. Appl Catal A Gen 157:91-103 (1997).

14 Oliveira MM, Schnitzler DC and Zarbin AJG, (Ti,Sn) $\mathrm{O}_{2}$ mixed oxides nanoparticles obtained by the sol-gel route. Chem Mater 15:1903-9 (2003).

15 Lin J, Yu JC, Lo D and Lam SK, Photocatalytic activity of rutile $\mathrm{Ti}_{1-\mathrm{x}} \mathrm{Sn}_{\mathrm{x}} \mathrm{O}_{2}$ solid solutions. J Catal 183:368-74 (1990).

16 Ishii K, Mizukami F, Niwa S, Toba M, Ushijima H and Sato T, Effects of raw materials and preparation methods of catalysts on the selective hydrogenation of ethyl phenylacetate. $J$ Am Oil Chem Soc 73:465-9 (1996).

17 Ragaini V, Carli R, Bianchi CL, Lorenzetti D and Vergani G, Fischer-Tropsch synthesis on alumina-supported ruthenium catalysts $\mathrm{I}$. Influence of $\mathrm{K}$ and $\mathrm{Cl}$ modifiers. Appl Catal A Gen, 139:17-29 (1996).

18 Narita, T, Miura H, Ohira M, Hondou H, Sugiyama K and Matsuda T, The effect of reduction temperature on the chemisorptive properties of $\mathrm{Ru} / \mathrm{Al}_{2} \mathrm{O}_{3}$ : Effect of chlorine. Appl Catal 32: 185-190 (1987).

19 Li J, Kitano M, Ye T, Sasase M, Yokoyama T and Hosono H, Chlorine-Tolerant Ruthenium Catalyst Derived Using the Unique Anion-Exchange Properties of $12 \mathrm{CaO} .7 \mathrm{Al}_{2} \mathrm{O}_{3}$ for Ammonia Synthesis. ChemCatChem 9: 3078-3083 (2017).

20 Benítez VM, Yori JC, Vera CR, Pieck CL, Grau JM and Parera JM, Characterization of transition-metal oxides promoted with oxoanions by means of test reactions. J Ind Eng Chem Res 44:1716-21 (2005).

21 Sánchez MA, Mazzieri VA, Oportus M, Reyes P and Pieck CL, Influence of Ge content on the activity of $\mathrm{Ru}-\mathrm{Ge}-\mathrm{B} / \mathrm{Al}_{2} \mathrm{O}_{3}$ catalysts for selective hydrogenation of methyl oleate to oleyl alcohol. Catal Today 213:81-6 (2013).

22 Hanaor DAH and Sorrell CC, Review of the anatase to rutile phase transformation. $J$ 
Mater Sci 46:855-74 (2011).

$23 \mathrm{Wu} \mathrm{L}$, Yu JC, Wang $\mathrm{X}$, Zhang $\mathrm{L}$ and $\mathrm{Yu} \mathrm{J}$, Characterization of mesoporous nanocrystalline $\mathrm{TiO}_{2}$ photocatalysts synthesized via a sol-solvothermal process at a low temperature. J Solid State Chem 178:321-8 (2005).

24 Gault FG, Mechanisms of skeletal isomerization of hydrocarbons on metals. Adv. Catal. 30:1-95 (1981)

25 Boudart M, Aldag A, Benson JE, Dougharty VA and Harkings CG, On the specific activity of platinum catalysts. J. Catal. 6:92-99 (1966).

26 Xie S, Qiao M, Li H, Wang W and Deng J-F, A novel Ru-B/SiO 2 amorphous catalyst used in benzene-selective hydrogenation. Appl Catal A Gen 176:129-34 (1999).

27 Moulder JF, Stickle WF, Sobol PE and Bomben KD, Handbook of X-ray Photoelectron Spectroscopy, ed by Chastain J, (1992).

28 Pouilloux Y, Autin F, Guimon C and Barrault J, Hydrogenation of Fatty Esters over Ruthenium-Tin Catalysts; Characterization and Identification of Active Centers. J Catal 176:215-24 (1998).

29 Van Der Steen PJ and Scholten JJF, Selectivity to cyclohexene in the gas phase hydrogenation of benzene over ruthenium, as influenced by reaction modifiers: II. Catalytic hydrogenation of benzene to cyclohexene and cyclohexane. Appl Catal 58:291-304 (1990).

30 Milone C, Neri G, Donato A, Musolino MG and Mercadante L, Selective Hydrogenation of Benzene to Cyclohexene on $\mathrm{Ru} / \gamma-\mathrm{Al}_{2} \mathrm{O}_{3}$. J Catal 159:253-8 (1996).

31 Mazzieri VA, Coloma-Pascual F, Arcoya A, L'Argentière PC and Fígoli NS, XPS, FTIR and TPR characterization of $\mathrm{Ru} / \mathrm{Al}_{2} \mathrm{O}_{3}$ catalysts. Appl Surf Sci 210:222-30 (2003).

32 Rodina VO, Ermakov DY, Saraev AA, Reshetnikov SI and Yakovlev VA, Influence of reaction conditions and kinetic analysis of the selective hydrogenation of oleic acid toward fatty alcohols on $\mathrm{Ru}-\mathrm{Sn}-\mathrm{B} / \mathrm{Al}_{2} \mathrm{O}_{3}$ in the flow reactor. Appl Catal B Environ 209:611-20 (2017). 
33 Adkins SR and Davis BH, The chemical state of tin in platinum-tin-alumina catalysts. $J$ Catal 89:371-9 (1984).

34 Sexton BA, Hughes AE and Foger K, An X-ray photoelectron spectroscopy and reaction study of Pt-Sn catalysts. J Catal 88:466-77 (1984).

$35 \mathrm{Gu}$ Q, Long J, Fan L, Chen L, Zhao L and Lin H, Single-site Sn-grafted Ru/TiO photocatalysts for biomass reforming: Synergistic effect of dual co-catalysts and molecular mechanism. J Catal 303:141-55 (2013).

36 Elmasides C, Kondarides DI, Grünert W and Verykios XE, XPS and FTIR Study of $\mathrm{Ru} / \mathrm{Al}_{2} \mathrm{O}_{3}$ and $\mathrm{Ru} / \mathrm{TiO}_{2}$ Catalysts: Reduction Characteristics and Interaction with a MethaneOxygen Mixture (1999).

37 Parera, JM and Fígoli NS, Reactions in the commercial reformer, in Catalytic Naphtha Reforming: Science and Technology, ed by Antos GJ, Aitani AM and Parera JM. Marcel Dekker Inc., Marcel Dek. New York, pp 45-78 (1995).

38 Edgar MD, Catalytic Reforming of Naphtha in Petroleum Refineries, in Applied Industrial Catalysis, ed by Bruce EL, Academic Press, New York, pp 124-48 (1983).

39 Luo G, Yan S, Qiao M, Zhuang J and Fan K, Effect of tin on $\mathrm{Ru}-\mathrm{B} / \gamma-\mathrm{Al}_{2} \mathrm{O}_{3}$ catalyst for the hydrogenation of ethyl lactate to 1,2-propanediol. Appl Catal A Gen 275:95-102 (2004).

40 Pouilloux Y, Piccirilli A and Barrault J, Selective hydrogenation into oleyl alcohol of methyl oleate in the presence of $\mathrm{Ru}-\mathrm{SnAl}_{2} \mathrm{O}_{3}$ catalysts. J Mol Catal A Chem 108:161-6 (1996). 41 Sánchez MA, Mazzieri VA, Vicerich MA, Vera CR and Pieck CL, Ru-Sn-B/Al $\mathrm{O}_{3}$ catalysts for selective hydrogenation of methyl oleate: Influence of the Ru/Sn Ratio. J of Chem 2015:1-7 (2015).

42 Yuan P, Liu ZY, Zhang WQ, Sun HJ, Liu SC, Cu- $\mathrm{Zn} / \mathrm{Al}_{2} \mathrm{O}_{3}$ Catalyst for the Hydrogenation of Esters to Alcohols. Chin J Catal 31:769-75 (2010). 
Table 1. Surface area, pore volume, pore size and average particle size determined for the four studied catalysts.

\begin{tabular}{lllll}
\hline Physical property & $\mathbf{3 0 0}^{\mathbf{}} \mathbf{C}$-CI & $\mathbf{5 0 0}^{\mathbf{}} \mathbf{C}-\mathbf{C I}$ & $\mathbf{3 0 0}^{\mathbf{}} \mathbf{C}$-IW & $\mathbf{5 0 0}^{\mathbf{0}} \mathbf{C}$-IW \\
\hline Surface area $\left(\mathrm{m}^{2} \mathrm{~g}^{-1}\right)$ & 93 & 38 & 103 & 48 \\
Pore volume $\left(\mathrm{cm}^{3} \mathrm{~g}^{-1}\right)$ & 0.21 & 0.22 & 0.25 & 0.25 \\
Pore size (nm) & 7.3 & 16.6 & 7.2 & 15.2 \\
$\mathrm{TiO}_{2}$ average particle size $(\mathrm{nm}) *$ & 9 & 14 & 9 & 16 \\
\hline
\end{tabular}

* determined by XRD. 
Table 2: $\mathrm{Ru}, \mathrm{Sn}, \mathrm{B}$ and chlorine contents, and cyclohexane conversion of $\mathrm{TiO}_{2}$ supported catalysts prepared by different methods at different pre-calcination temperatures.

\begin{tabular}{llllll}
\hline Catalyst & Ru (wt\%) & Sn (wt\%) & B (wt\%) & Cl (wt\%) & CH (\%) \\
\hline $300{ }^{\circ} \mathrm{C}-\mathrm{CI}$ & 1.29 & 2.86 & 0.32 & 0.42 & 6.8 \\
$500{ }^{\circ} \mathrm{C}-\mathrm{CI}$ & 1.27 & 2.76 & 0.20 & 0.35 & 3.0 \\
$300{ }^{\circ} \mathrm{C}-\mathrm{IW}$ & 1.28 & 2.97 & 0.31 & 0.32 & 6.1 \\
$500{ }^{\circ} \mathrm{C}-\mathrm{IW}$ & 1.26 & 2.92 & 0.18 & 0.29 & 2.7 \\
\hline
\end{tabular}

$\mathrm{CH}$ : cyclohexane conversion 
Table 3. Surface atomic ratio of Ru and Sn species determined by XPS.

\begin{tabular}{|c|c|c|c|c|}
\hline Catalyst & $\mathbf{R u} / \mathbf{T i}$ & $\overline{\mathrm{Sn} / \mathrm{Ti}}$ & Sn/Ru & $R u^{\circ} /\left(R u^{n+}+R u^{\circ}\right)$ \\
\hline $300^{\circ} \mathrm{C}-\mathrm{CI}$ & 0.053 & 0.364 & 6.87 & 0.33 \\
\hline $500{ }^{\circ} \mathrm{C}-\mathrm{CI}$ & 0.031 & 0.279 & 9.00 & 0.55 \\
\hline $300^{\circ} \mathrm{C}-\mathrm{IW}$ & 0.068 & 0.474 & 6.97 & 0.48 \\
\hline $500^{\circ} \mathrm{C}-\mathrm{IW}$ & 0.062 & 0.305 & 4.92 & 0.79 \\
\hline
\end{tabular}




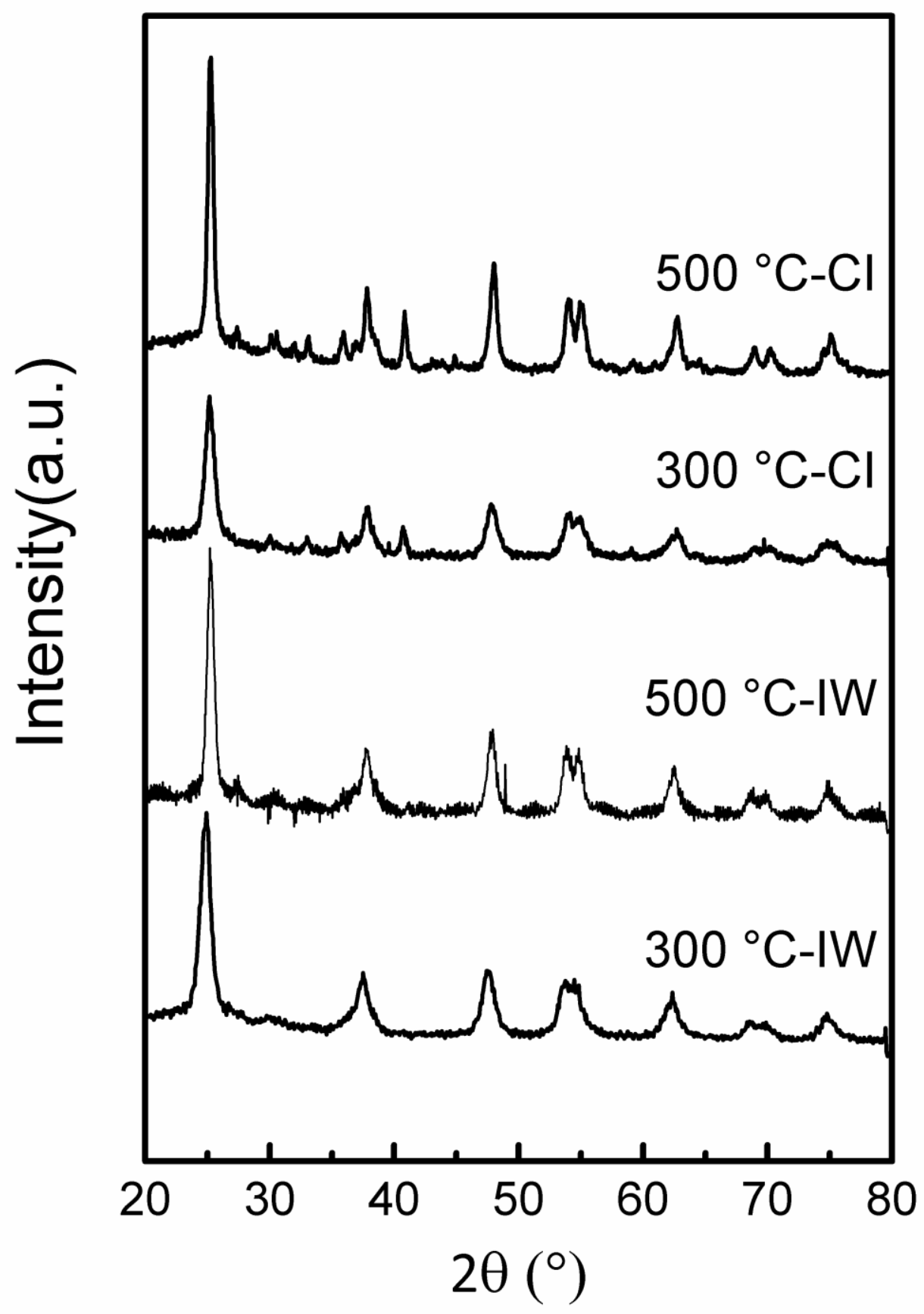

Figure 1. XRD patterns of the catalysts prepared by IW and CI method on the titania support calcined at different temperatures. 


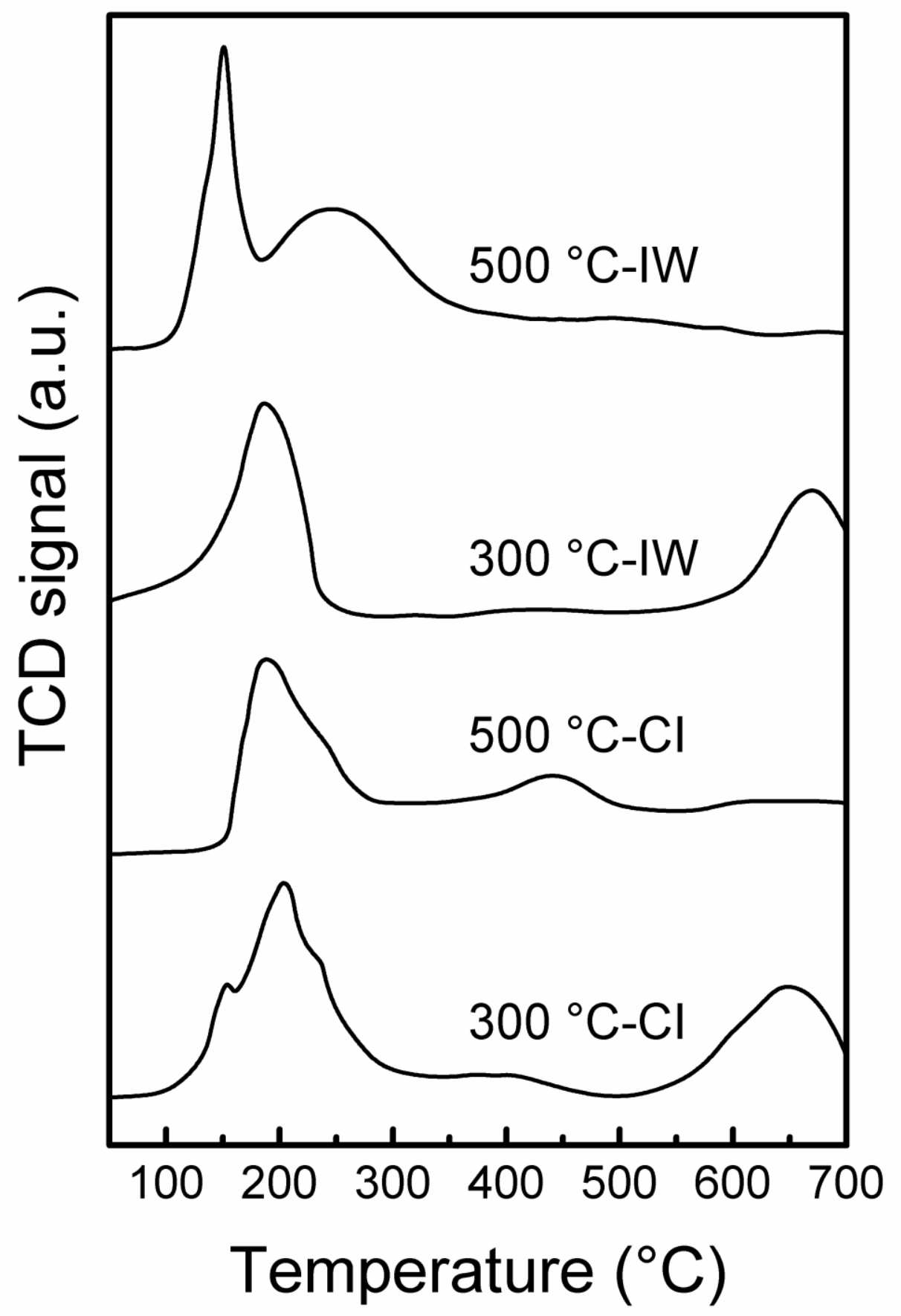

Figure 2. TPR of the catalysts prepared by IW and CI method on the titania support calcined at different temperatures. 


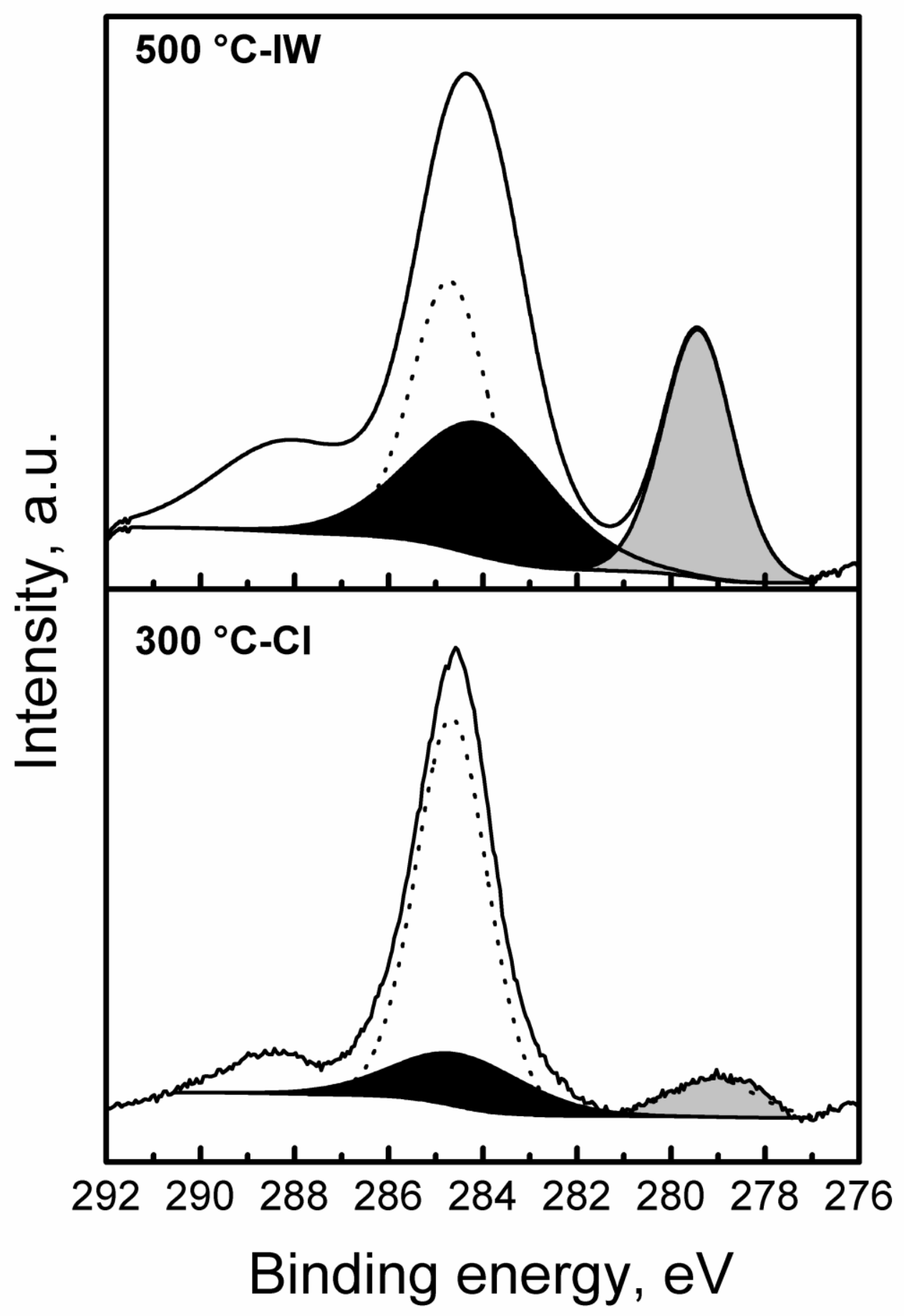

Figure 3. XPS spectra in the Ru 3d region of the $500{ }^{\circ} \mathrm{C}$-IW and $300{ }^{\circ} \mathrm{C}-\mathrm{CI}$ catalysts. Grey shaded peak, black shaded peak and dashed line corresponds to $\mathrm{Ru}^{\circ}, \mathrm{Ru}^{\delta+}$ and $\mathrm{C} 1 \mathrm{~s}$, respectively. 


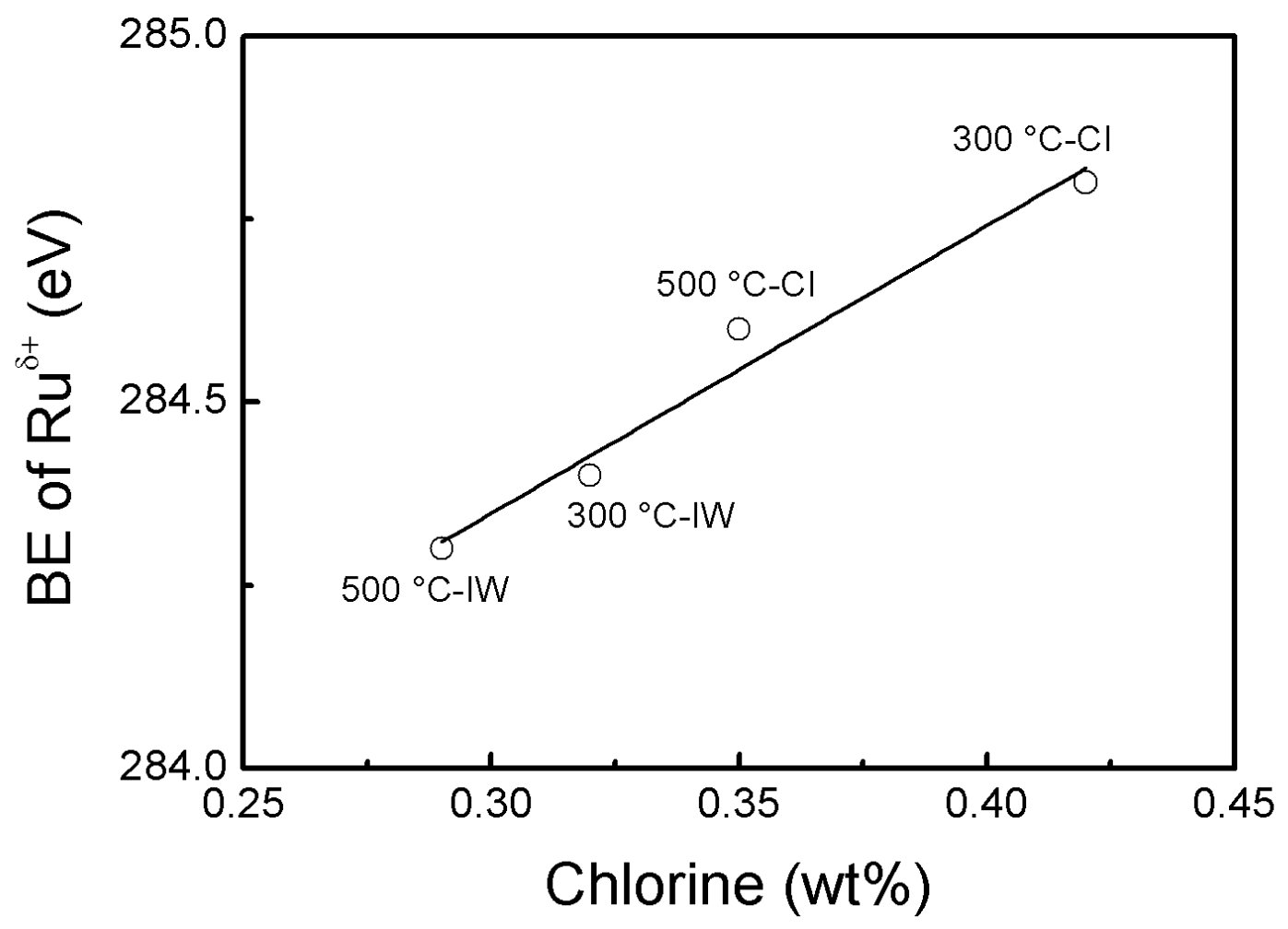

Figure 4. Binding energy of the $\mathrm{Ru}^{\delta+}$ species in the $\mathrm{Ru} 3 \mathrm{~d}_{5 / 2}$ region as a function of the chlorine content of the catalysts. 

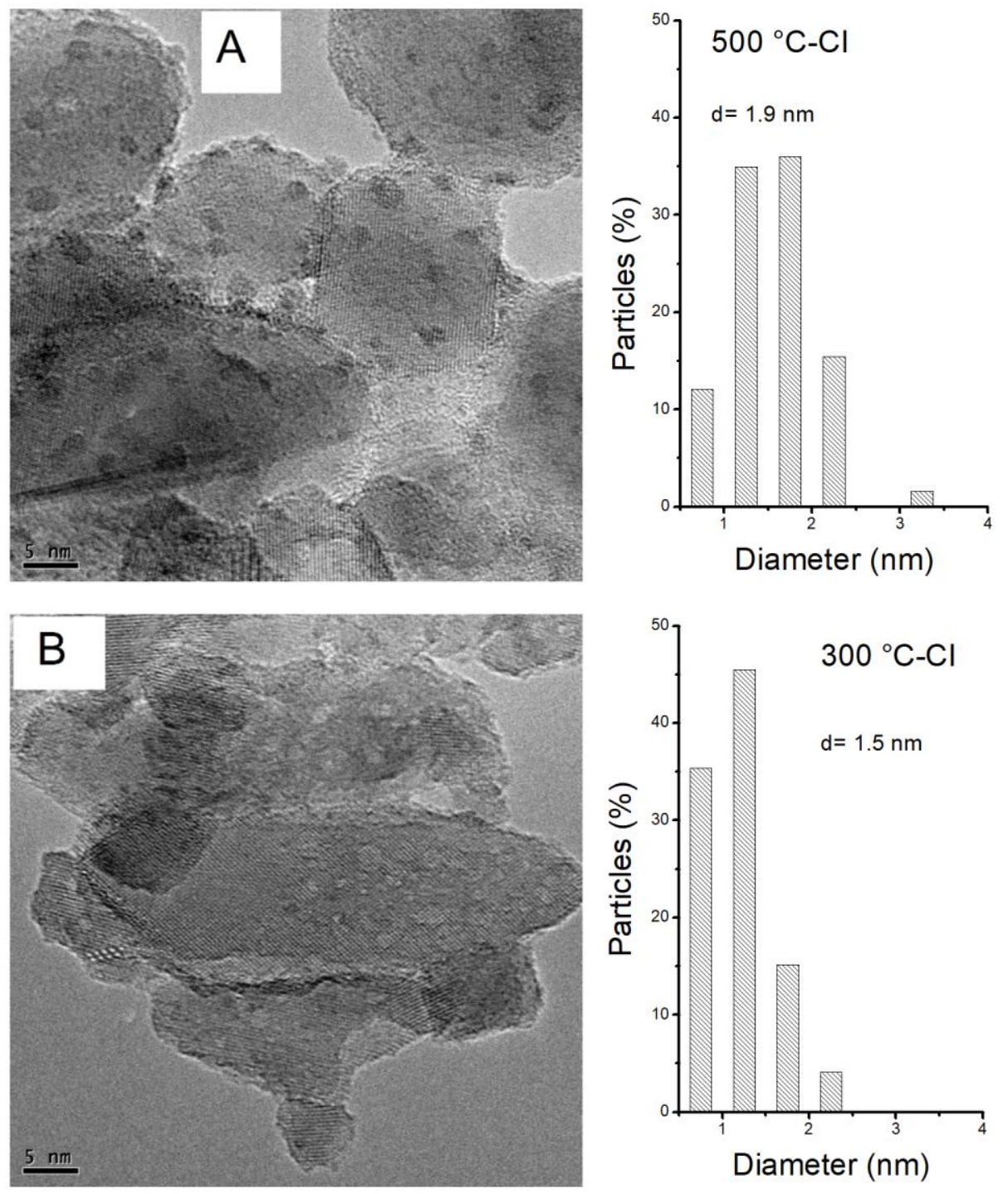

Figure 5: TEM pictures and particle size distributions of (A) $500{ }^{\circ} \mathrm{C}$-CI catalyst $(630$ particles analyzed); (B) $300{ }^{\circ} \mathrm{C}-\mathrm{CI}$ catalyst (614 particles analyzed). 

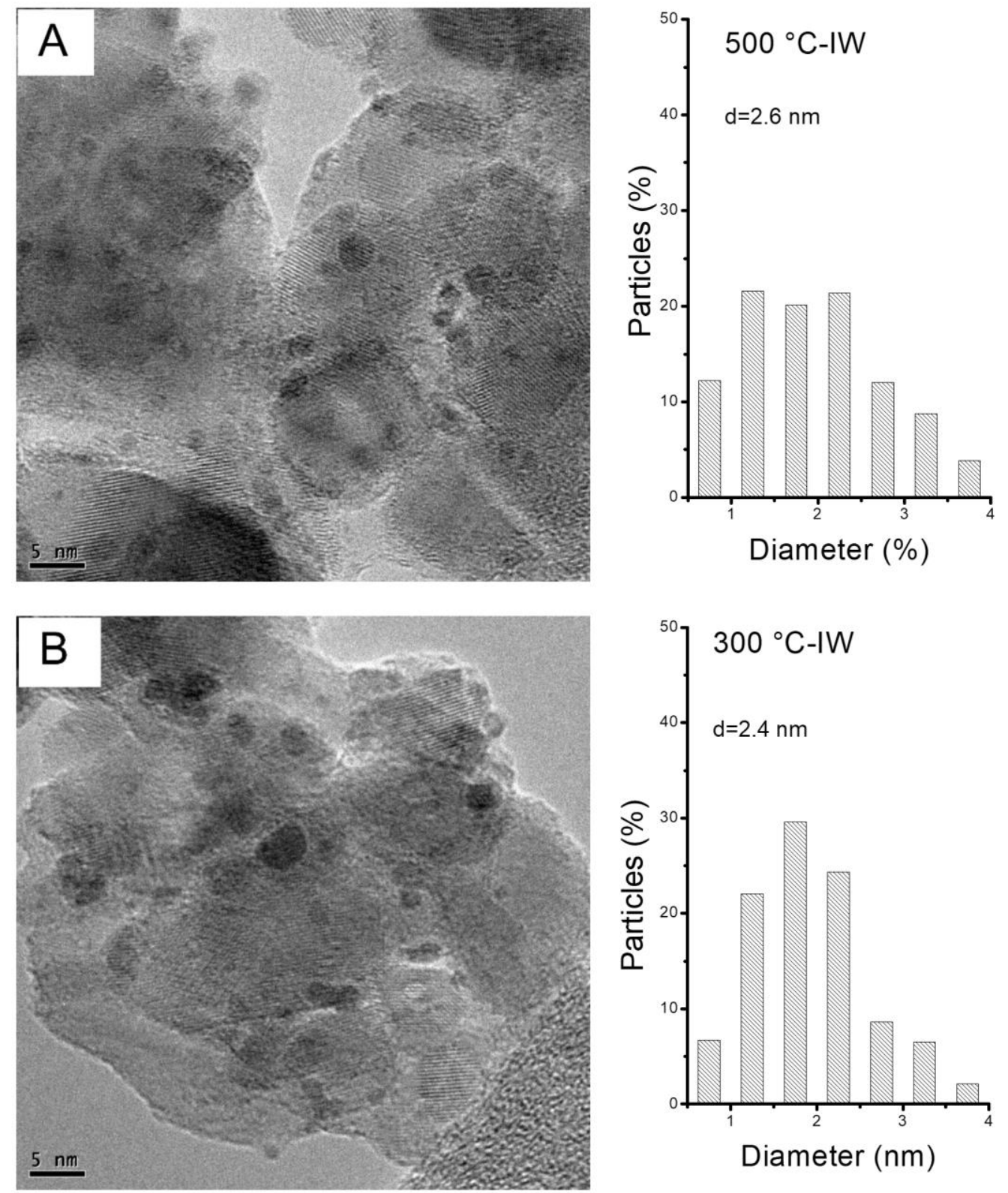

Figure 6: TEM pictures and particle size distributions of (A) $500{ }^{\circ} \mathrm{C}$-IW catalyst (491 particles analyzed); (B) $300{ }^{\circ} \mathrm{C}$-IW catalyst (476 particles analyzed). 


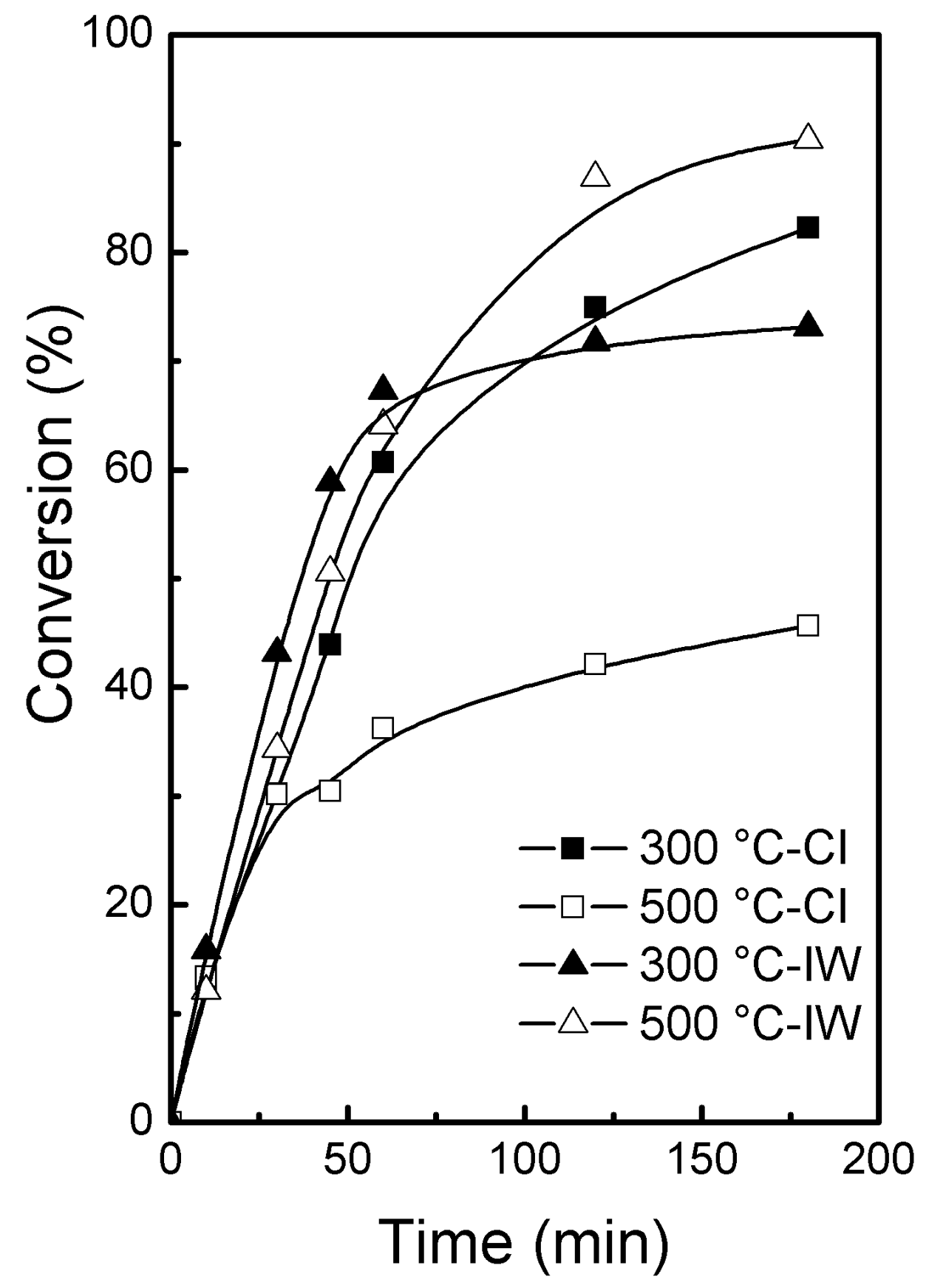

Figure 7. Conversion of methyl oleate as a function of the reaction time obtained with the four studied catalysts. 


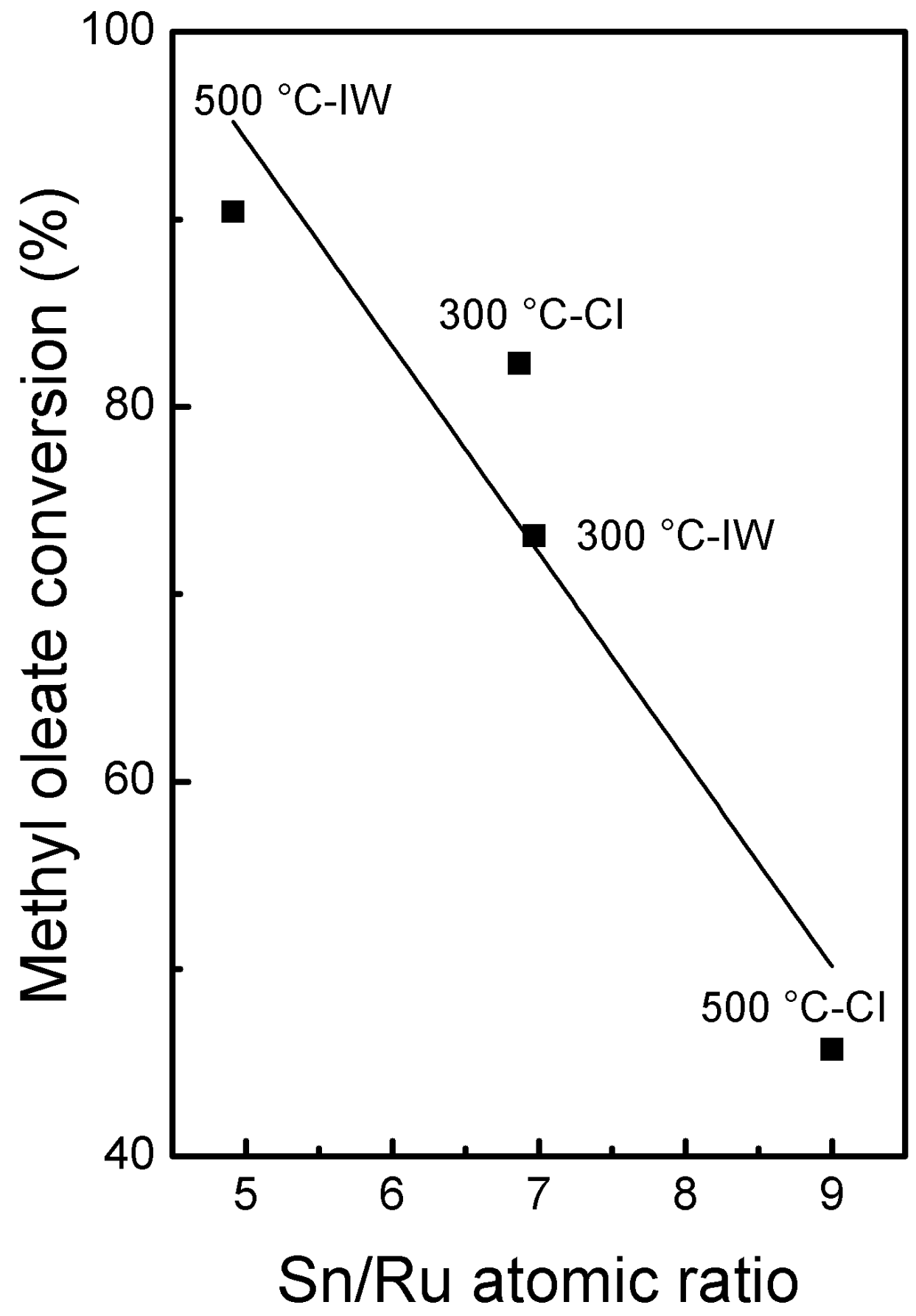

Figure 8. Conversion of methyl oleate at $180 \mathrm{~min}$ reaction time as a function of the $\mathrm{Sn} / \mathrm{Ru}$ atomic ratio obtained by XPS. 


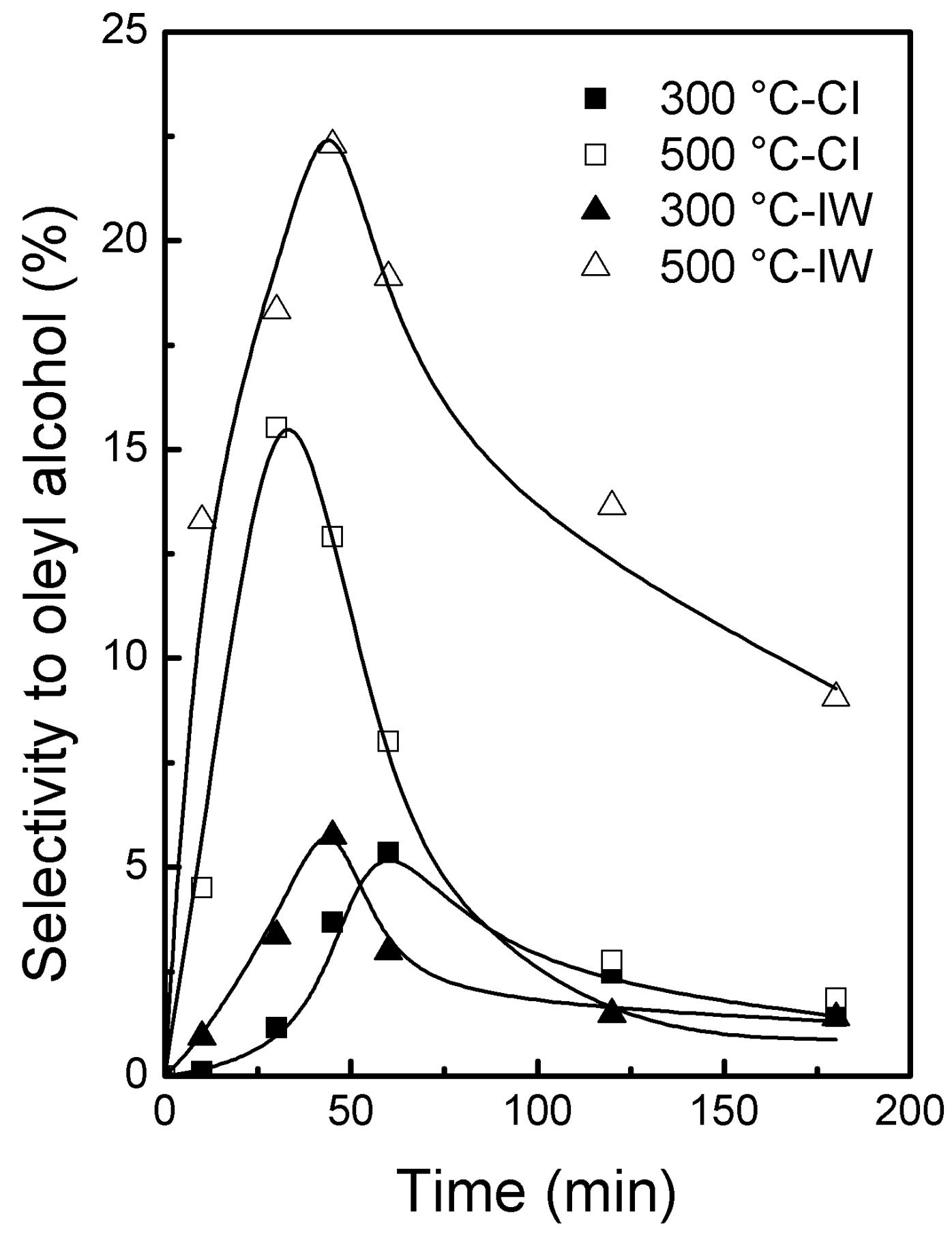

Figure 9. Selectivity to oleyl alcohol as a function of the reaction time obtained with the four studied catalysts. 


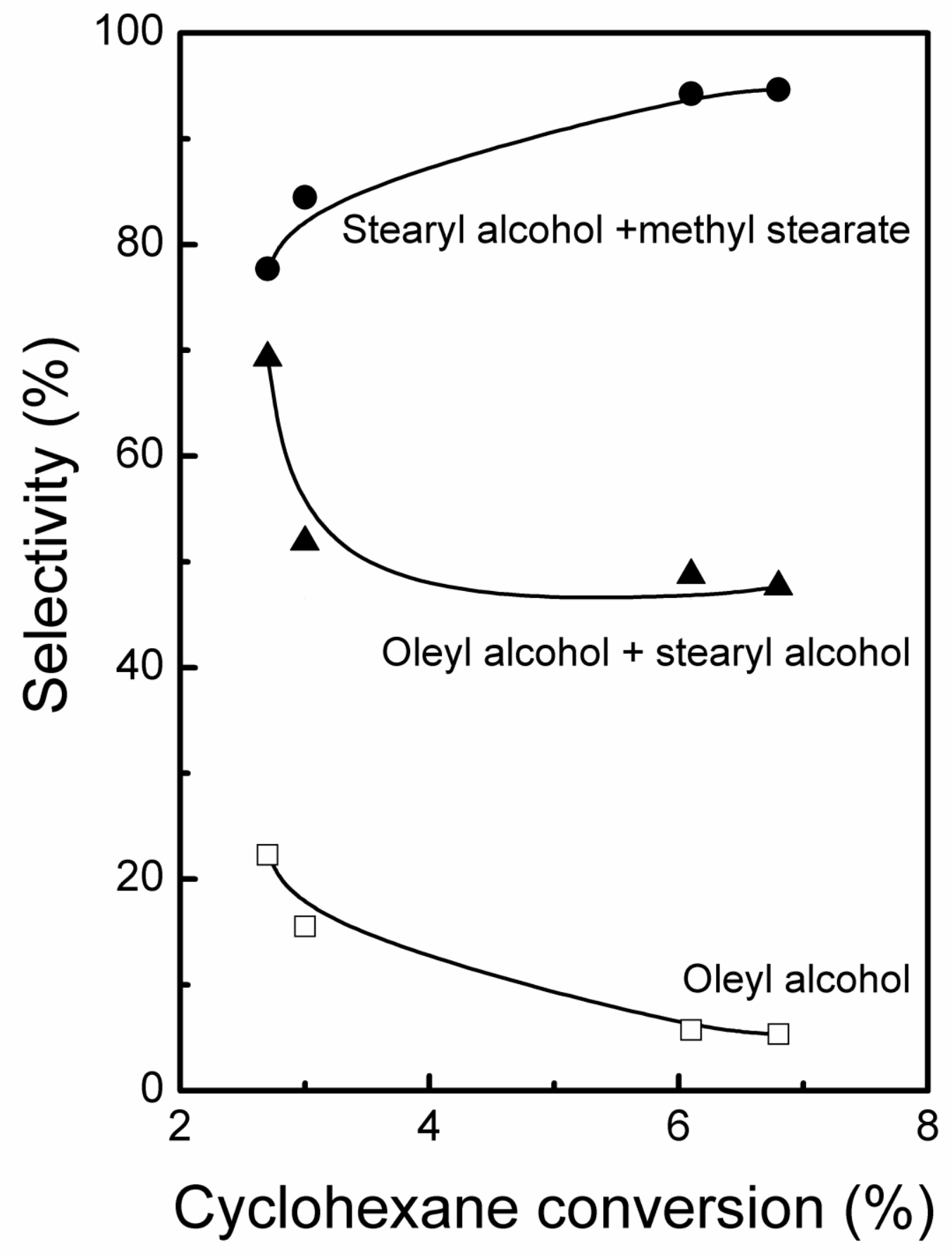

Figure 10. Selectivity to oleyl alcohol, the sum of the selectivity to stearyl alcohol and methyl stearate and the sum of the selectivity to oleyl alcohol and stearyl alcohol as a function of the conversion of cyclohexane (values taken at the maximum selectivity to oleyl alcohol). 


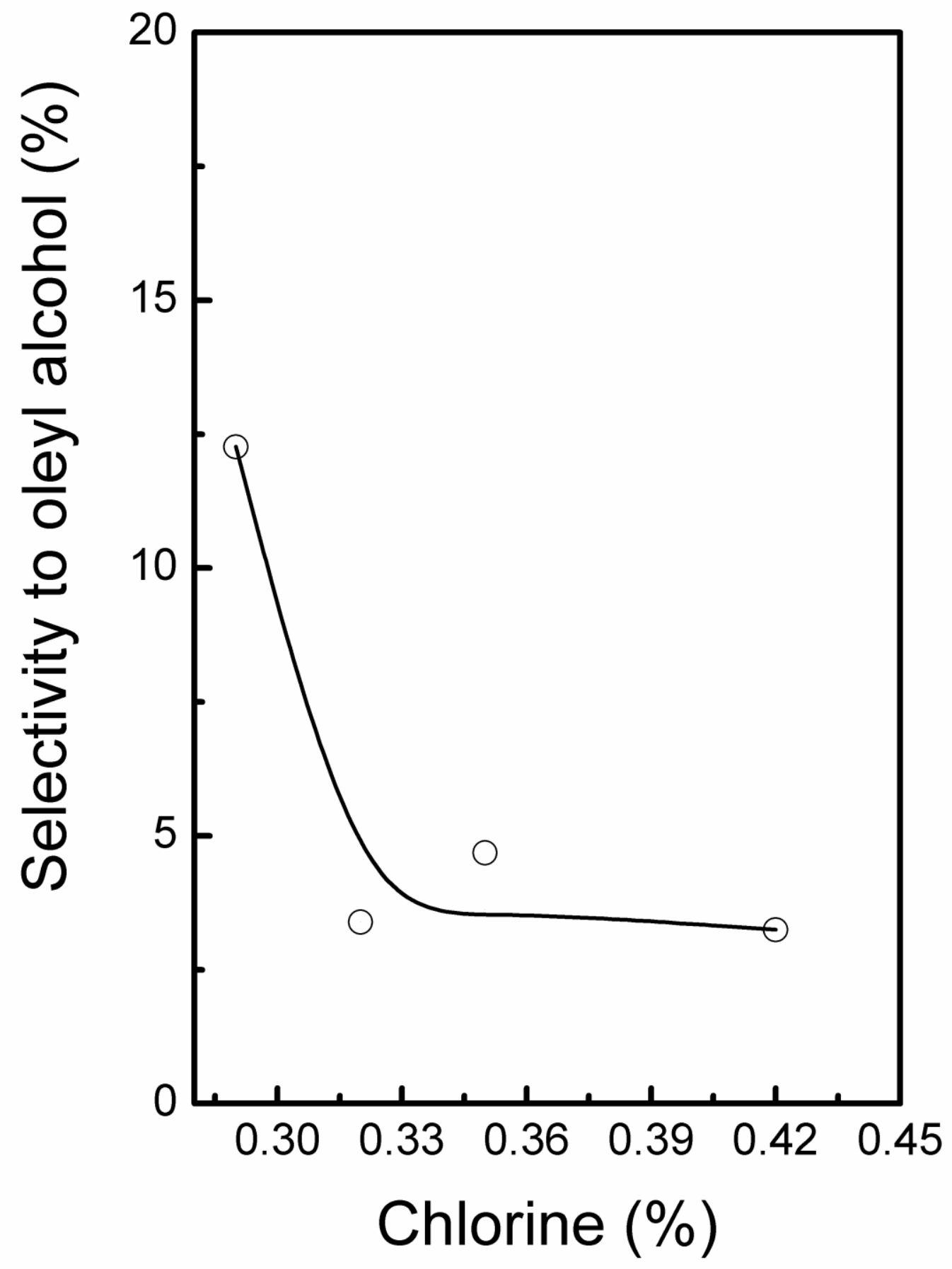

Figure 11. Maximum selectivity to oleyl alcohol obtained in each catalyst as a function of the chlorine content. 